\section{Are endoscopic mucosal resection and endoscopic submucosal dissection risky for patients with cirrhosis?}

Endoscopic mucosal resection (EMR) and endoscopic submucosal dissection (ESD) have become a standard treatment in selected cases of early gastric cancer $[1,2]$. The risk of complications may increase in patients with cirrhosis, due both to severe clotting impairment and to decreased platelet counts [3]. We present our experience in three patients with cirrhosis.

A 68-year-old woman with cryptogenic cirrhosis and esophageal varices, who had normal laboratory parameters and platelet count, was diagnosed with a high-grade gastric adenoma. ESD was decided on. Lesion margins were marked. A solution of mixed saline, adrenaline, and indigo-carmine was used for submucosal injection. Circumferential incision and submucosal dissection were carried out using a HookKnife and an ITknife2 (Olympus, Tokyo, Japan). A Coagrasper (Olympus) was used for preventive hemo- stasis. The lesion was removed en bloc in 61 minutes ( Figs. 1,2). Pathological examination revealed a high-grade gastric adenoma. A prophylactic antibiotic was administered. Endoscopy at 6-month follow-up showed no recurrence.

A 69-year-old man was diagnosed with decompensated cryptogenic cirrhosis (esophageal varices and ascites). Serum bilirubin and albumin levels were $1.9 \mathrm{mg} / \mathrm{dL}$ and $2.2 \mathrm{~g} / \mathrm{dL}$ respectively. Platelet count was $59 \times 10^{3} / \mu \mathrm{L}$ and INR was 1.42. Endoscopic evaluation showed a sessile polyp (width $10 \mathrm{~mm}$ ) in the gastric body. The polyp was elevated by administering a mixture of saline and adrenaline, and was then removed en bloc using a polypectomy snare. Pathological examination revealed a grade 1 neuroendocrine tumor. Prophylactic antibiotic therapy was administered.
A 55-year-old woman was diagnosed as having hepatitis $C$ virus-related cirrhosis. Blood chemistry was normal except for the platelet count $\left(91 \times 10^{3} / \mu \mathrm{L}\right)$. Five sessile polyps (the largest $15 \mathrm{~mm}$, the others $6-8 \mathrm{~mm}$ ) were seen in the gastric body during endoscopy. The largest polyp was elevated as described above and removed en bloc using a polypectomy snare. EMR with a ligation device was planned for the remaining polyps. The lesions were elevated, band ligation was applied, and EMR was performed below the band with a polypectomy snare ( $\bullet$ Figs. 3,4$)$. Pathological examination revealed grade 1 neuroendocrine tumor for all lesions. A prophylactic antibiotic was administered.

Patients with cirrhosis are at increased risk of developing gastric lesions [4]. Surgical treatment in these patients is associated with high mortality [5]. The risk of bleeding during ESD in patients with cirrhosis is reported to be $4 \%-33 \%$. INR below 1.5 and a platelet count above $50 \times 10^{3} / \mu \mathrm{L}$ are likely to be safe thresholds for endoscopic resection [3,6-8]. There is a risk of sepsis in cirrhotic patients due to impairment of defensive mechanisms [9]. Prophylactic antibiotics can reduce the risk of bacteremia and sepsis.
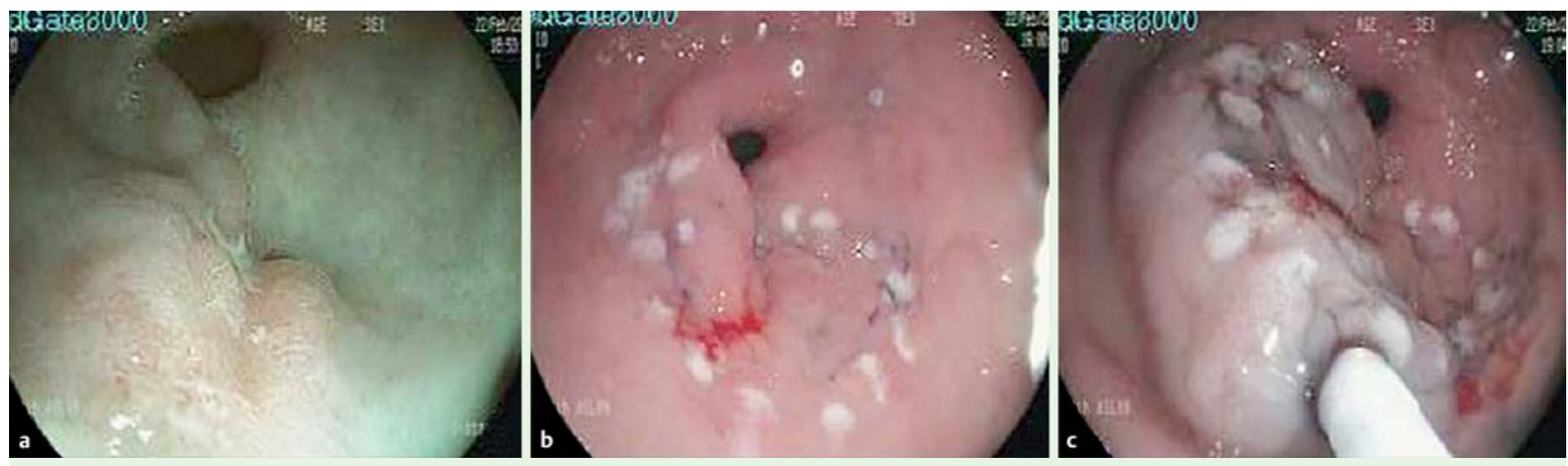

Fig. 1 a Endoscopic appearance (i-scan) of gastric lesion. b Marking the lesion with the HookKnife. c Submucosal injection.
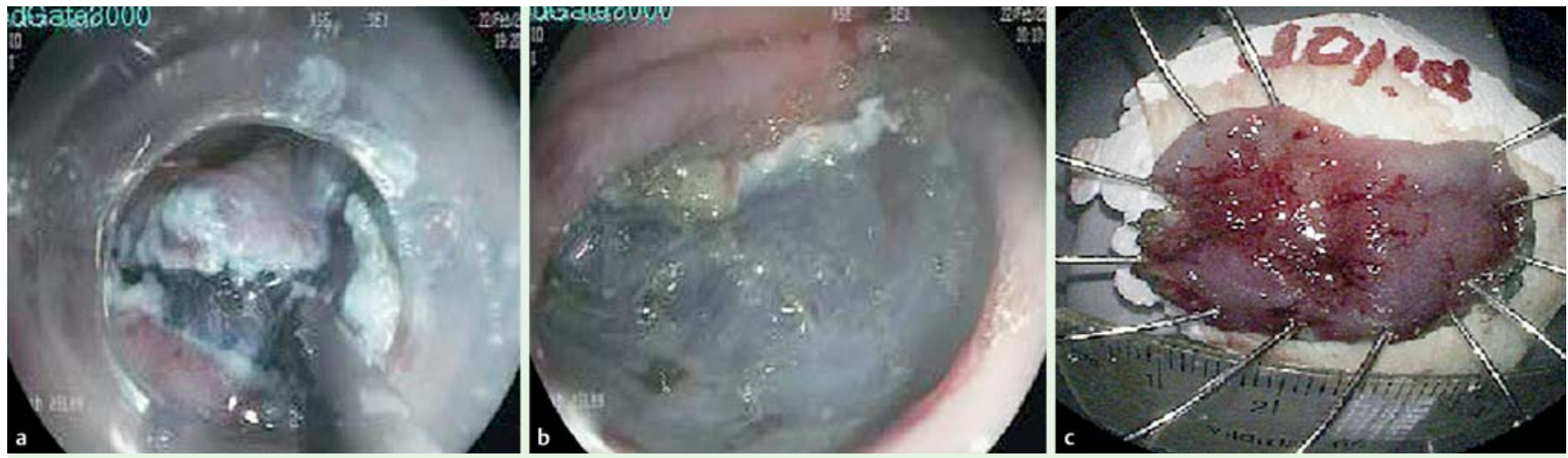

Fig. 2 a View of submucosal tissue through endoscope hood. b Mucosal defect after endoscopic submucosal dissection. $\mathbf{c}$ Resected specimen. 

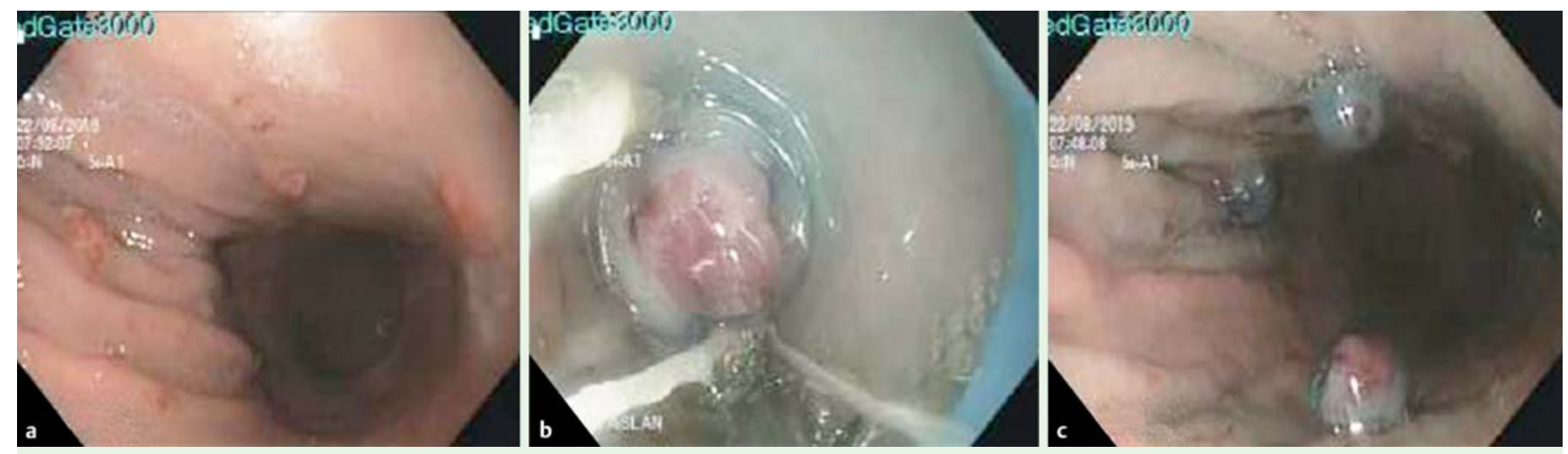

Fig. 3 a Endoscopic appearance of gastric lesion. b, c Application of endoscopic band ligation to lesions.
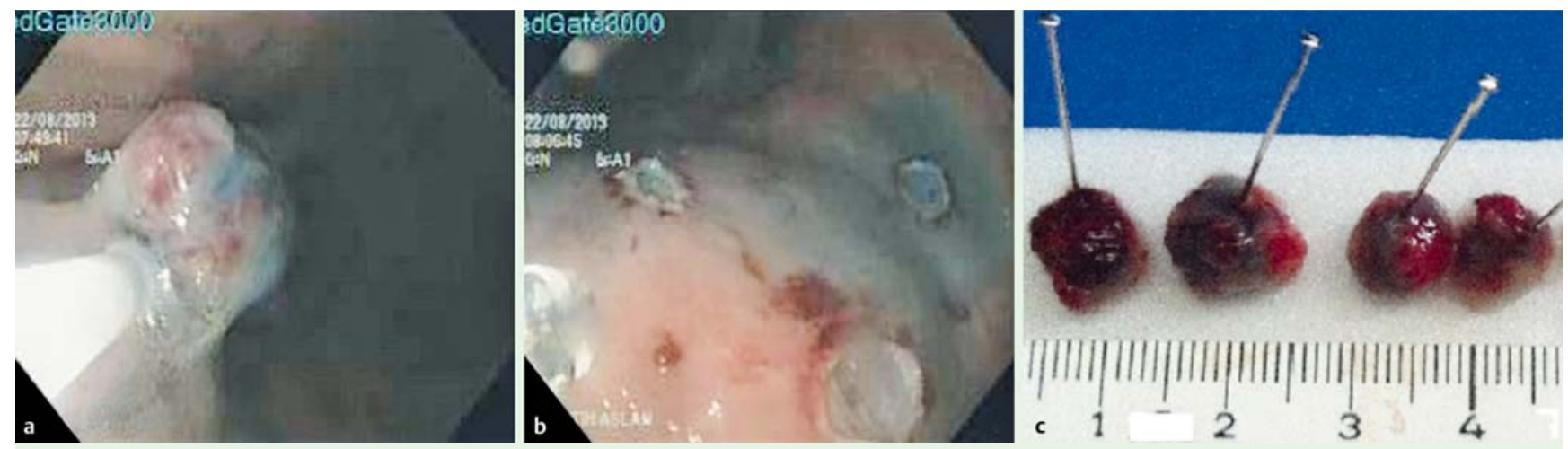

Fig. 4 a View after endoscopic resection with snare. b Mucosal defects after endoscopic mucosal resection. c Resected specimens

Endoscopy_UCTN_Code_TTT_1AO_2AG

\section{Competing interests: None}

Fatih Aslan' ${ }^{1}$, Zehra Akpinar', Ali Riza Seren², Emrah Alper ${ }^{1}$, Cem Cekic ${ }^{1}$, Nese Ekinci ${ }^{3}$, Sezgin Vatansever ${ }^{1}$, Belkis Unsal ${ }^{1}$

${ }^{1}$ Department of Gastroenterology, Katip Celebi University Ataturk Training and Research Hospital, Izmir, Turkey

2 Department of Anesthesiology and Reanimation, Katip Celebi University Ataturk Training and Research Hospital, Izmir, Turkey

${ }^{3}$ Department of Pathology, Katip Celebi University Ataturk Training and Research Hospital, Izmir, Turkey

\section{References}

1 Yamamoto H, Kita H. Endoscopic therapy of early gastric cancer. Best Pract Res Clin Gastroenterol 2005; 19: 909-926

2 Soetikno R, Kaltenbach $T$, Yeh $R$ et al. Endoscopic mucosal resection for early cancers of the upper gastrointestinal tract. J Clin Oncol 2005; 23: 4490-4498

3 Ferro D, Angelico F, Caldwell SH et al. Bleeding and thrombosis in cirrhotic patients: what really matters? Dig Liver Dis 2012; 44: 275-279

4 Zullo A, Romiti A, Tomao $S$ et al. Gastric cancer prevalence in patients with liver cirrhosis. Eur J Cancer Prev 2003; 12: 179-182

5 Douard R, Lentschener C, Ozier Yet al. Operative risks of digestive surgery in cirrhotic patients. Gastroenterol Clin Biol 2009; 33: $555-564$

6 Kwon YL, Kim ES, Lee KI et al. Endoscopic treatments of gastric mucosal lesions are not riskier in patients with chronic renal failure or liver cirrhosis. Surg Endosc 2011; 25: 1994-1999

7 Repici A, Pagano N, Hassan C et al. Endoscopic submucosal dissection of gastric neoplastic lesions in patients with liver cirrhosis: a systematic review. J Gastrointestin Liver Dis 2012; 21: 303 - 307

8 Zullo A, Hassan C, Bruzzese V. Comment to "Bleeding and thrombosis in cirrhotic patients: what really matters?" Dig Liver Dis 2012; 44: 1049
9 Garcia-Tsao G. Current management of the complications of cirrhosis and portal hypertension: variceal hemorrhage, ascites, and spontaneous bacterial peritonitis. Gastroenterology 2001; 120: 726-748

\section{Bibliography}

Dol http://dx.doi.org/

10.1055/s-0034-1364946

Endoscopy 2014; 46: E149-E150

(c) Georg Thieme Verlag KG

Stuttgart · New York

ISSN 0013-726X

\section{Corresponding author \\ Fatih Aslan, MD}

Yali Mahallesi

I. Tarik Sari Caddesi

Aktas Evleri-1, B Blok

No: 16, Daire: 5

35310, Guzelbahce

Izmir

Turkey

drfatihaslan@hotmail.com 